\title{
Risk management and surveillance systems: A Model proposed for the provincial public hospital (CHP)
}

\author{
Chems-Eddouha Khassouani ${ }^{1, ~ *, ~ A b d e l l a t i f ~ A s r i ~}{ }^{2,}$, and Abdelmajid Soulaymani. * \\ ${ }^{1} \mathrm{Ph} . \mathrm{D}$, in charge of quality and risk management unit, Provincial hospital center of Ifrane, Morocco \\ ${ }^{2}$ Medical public health specialist, head of the health delegation and director of the provincial hospital center, Ifrane, Morocco \\ ${ }^{3}$ Professor, head of the center for doctoral studies, Faculty of sciences, university Ibn Tofail, Kenitra, Morocco
}

\begin{abstract}
During the Covid-19 pandemic, the provincial hospitals (CHP) of Morocco have demonstrated a remarkable capacity for reactivity. They were able to reorganize themselves to ensure the response to the pandemic and maintain basic functions. However, this reactivity alone does not prove their resilience in the face of new infections and possible disasters. The CHP must plan its responsiveness well in advance by building an intra-hospital health vigilance system that meets basic provincial requirements and that communicates with its internal and external environments.

A qualitative analysis, using the focus group method, on Ifrane hospital risk management system revealed that, the systems for notification and declaration of adverse events are set up under the responsibility of multiple actors and using multiple notification forms. The processes and procedures are not clear with an overlap between the activities of quality assurance, risk management and complaints treatment system. A lot of information does not arrive at its destination on time, which impacts decision-making. This work proposes a hospital risk management model with two systems, one for safety of care and the other for risk management, taking into account the missions of the CHP and the different sources of information. Key words: hospital, risks, surveillance system, model
\end{abstract}

\section{Introduction}

The health surveillance and vigilance systems attempt to monitor the risks of the occurrence of adverse events and to generate the health alert. In public hospitals in Morocco, these systems are recently implemented. Some vigilances are reglementary in the public health structures, such as patient safety ${ }^{\mathrm{a}}$, hemovigilance ${ }^{\mathrm{b}}$, pharmacovigilance ${ }^{c}$. The internal regulation of public hospitals of Morocco dedicated vigilance and security in its 2 articles 88 et $89^{\mathrm{d}}$. The national orientation towards hospital accreditation encourages the development of mechanisms for quality management and risk management at the healthcare facilities ${ }^{\mathrm{e}}$. The system for reporting adverse events related to care is recently introduced in public health structures ${ }^{\mathrm{f}}$. Actually, the most well anchored system in hospitals is the public health surveillance system which consist of the periodic reporting of certain diseases within the framework of health programs and the active surveillance system for notifiable diseases which was established in public hospitals since the publication of a ministerial circular ${ }^{\mathrm{g}}$. Other mechanisms for reporting adverse events were developed and a complaints unit was created to collect population claims. The start point of running these different systems is the notification of events despite using different processes and methods. The implementation of risk management at the provincial

amplantation des neuf recommandations de l'OMS Circulaire $\mathrm{n}^{\circ} 97,2008$

${ }^{\mathrm{b}}$ Loi $\mathrm{n}^{\circ}$ 34-94 relative au don, au prélèvement et à l'utilisation du sang humain

c Organisation du système national de pharmacovigilance,

Circulaire $\mathrm{n}^{\circ} 003,2016$

${ }^{\mathrm{d}}$ Règlement intérieur des hopitaux,2010

${ }^{\text {e }}$ Loi cadre 34-09 relative au système de santé et de l'offre de soins, 2011 hospital center (CHP) of Ifrane was chosen as an approach to improve the quality of care and services by installing a system with 5 components:

\subsection{Adverse event reporting system}

It is used to notify adverse events related to the care practice within the fields of pharmacovigilance, vigilance of medical devices, hemovigilance and incidents and accidents which can be reported manually or via an electronic platform designed in the context of patient safety.

\subsection{Nosocomial infections reporting system}

This is a local system which consists of notification by caregivers or during the results of samples taken from surfaces by the operational hygiene team.

\subsection{Reporting system for notifiable diseases}

It is rather an active epidemiological surveillance, conducted by the hospital epidemiological focal point in charge of checking every day in service records, information on 23 diseases and transmitting the observed and documented cases to be declared by clinicians

\footnotetext{
${ }^{\mathrm{f}}$ Instauration d'un dispositif de notification des événements indésirables lés aux soins Circulaire ${ }^{\circ} 83$ du 21 novembre, 2014

$\mathrm{g}$ Organisation de la notification des maladies à déclaration obligatoire (MDO)et des évènements inhabituels (EI) en milieu hospitalier, Circulaire n²7,2019
}

\footnotetext{
* Corresponding author: ckhassouani@hotmail.com
} 
immediately or after confirmation to the health monitoring unit located at the health delegation of the province

\subsection{Reporting System specific to health programs}

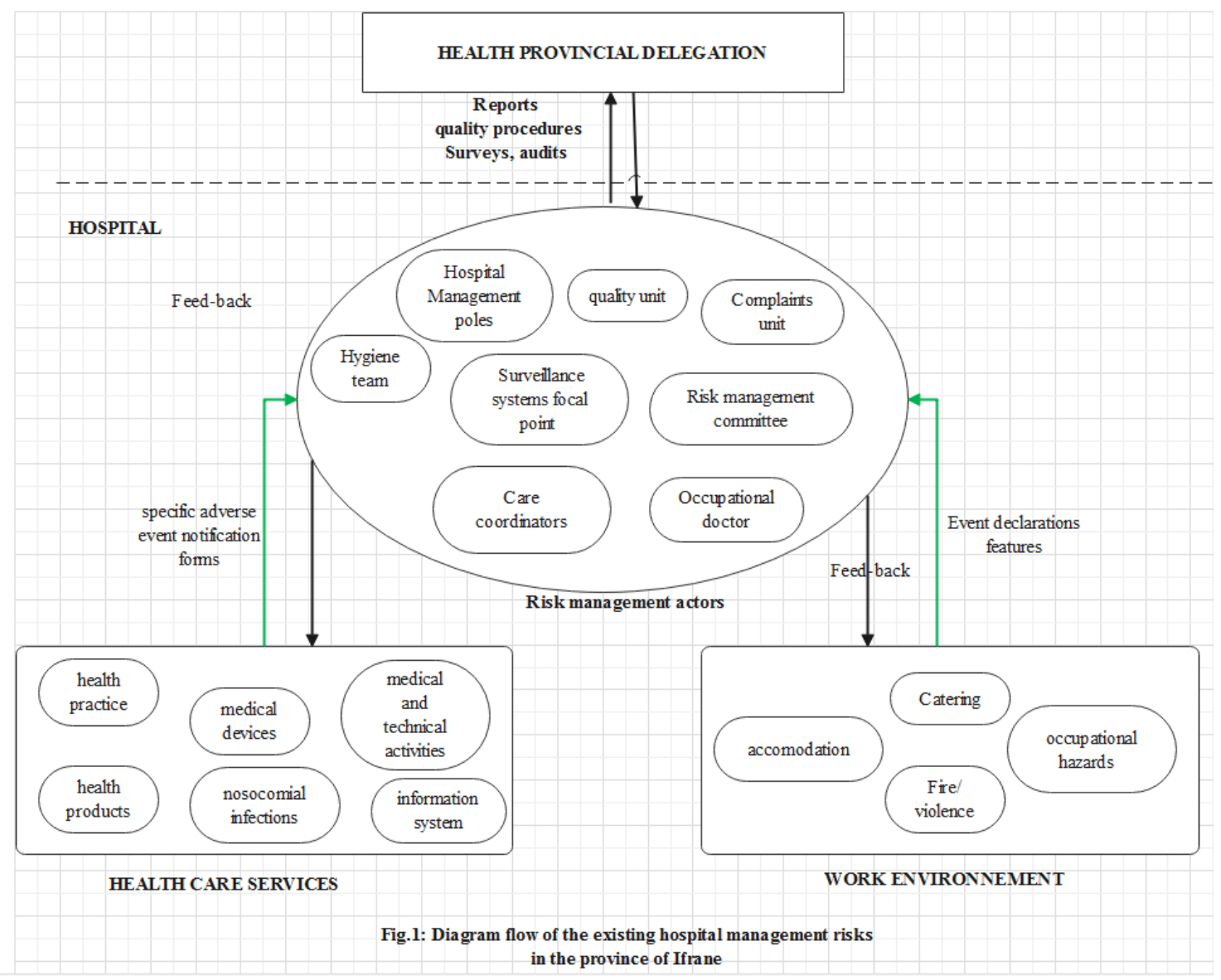

\subsection{Reporting and processing system of complaints}

The complaints and claims of users and the population are notified via both of a web application, mail or orally to the claims processing unit. They should be investigated and require a response to written complaints.

The fig 1 diagrams the current systems relating to risk management and shows the complexity of information flows.

As part of improving the quality of care, an evaluation of the risk management processes implemented was necessary to improve their efficiency, reliability and timelines.

\section{Methods}

We have adopted the focus group debate, a qualitative method for gathering local perceptions in terms of risk management $[1,2]$. A grid of 6 open questions served as a reference for 4 homogeneous groups (group 1: nursing
This system concerns programs such as bronchoalveolitis, gastroenteritis, poisoning cases which are reported directly to the health provincial monitoring unit, through monthly reports. staff, group 2: administrative staff; group 3: doctors and interns; group 4: laboratory staff; group 5: CHP supporting staff). Each focus group included a maximum of 8 people. Several meetings were organized to collect a large number of responses.

Each session was facilitated by a moderator. An observer was responsible for recording all responses. Explanations were provided in Moroccan dialectal Arabic when needed.

The themes addressed aim to assess the level of implementation of the risk management system, the staff support and their knowledge about risk management methods and tools. The answers were grouped by topic and saved in a Word file immediately after each focus group.

\section{Results and discussions}

Several focus group sessions were organized. The analysis of the discussions was carried out in the presence of some participants. The responses obtained showed that the majority was aware of the risks present in the hospital 
and well defined their typology but did not know about the managing processes implemented. Biological risks are very well described but only participants who have been victims of an accident knew about the management process. Nosocomial infections are often notified to the Committee for the fight against nosocomial infections (C.L.I.N) to trigger disinfection operations. Doctors and head of nurses seemed to be familiar with epidemiological surveillance and often report directly to the provincial delegation, especially in the face of suspected or probable cases of covid-19. Going through the epidemiology focal point of the hospital is not always useful. The transmission of periodically reports of health programs data under passive surveillance by the head of nurses was partially known. In the other hand, participants were ignoring patient safety procedures. The discussions revealed that the notification forms are not available in all hospital departments and even if they are, health workers do not have enough time to fill them in and prefer to notify serious cases by phone. In addition to these constraints, there was a problem of feed-back. The example cited was the non-reactivity to materiovigilance problems which remained unresolved despite several notifications and correspondence sent to the complaints and claims unit and to the central level. Some participants thought that quality assurance activities are sufficient to avoid risks, others believe that quality of care indicators and audits of death and near miss cases should be leveraged for better decision making. Medical specialists used to report adverse events especially cases of nosocomial infections, pharmacovigilance and materiovigilance, assaults and poor working conditions during specialist outpatient consultations and found that the responsiveness of the administration was insufficient particularly for specialities delivered outside the hospital such as the hemodialysis. Likewise, declarations of health workers exhaustion were not taken into account.

According to these focus group discussions, we found out that the risk management systems put in place still to be at its early stages, not clear and not generalized. This has prompted us to think about improving its organization.

\subsection{A proposal model for hospital risk management}

The model suggested in this paper, takes as a starting point, the need of a hospital project made in consultation with the advisory bodies of the hospital center where both of the medical and the care plans should be described. A hospital quality policy must be developed and broken down into action programs as suggested by several authors $[3,4]$. For the implementation of this policy, a cross-cutting leadership is needed to advocate the principles of transparency in the dissemination of information.

The first step of the model action plan will be a designation of referents at each service. The policy of quality must describe the organization and operation of the risk management system. The reorganization of the care channels, including the health emergency flow and the coordination mechanisms, must be part of the policy of quality. Standards of good practice relating to patient management and infection prevention and control procedures should be available as an input to the process. The success of the adverse event reporting system relies primarily on trust, a culture of "no blame" and capacity building in quality management.

This model is inspired by the model of the Center for Disease Control and Prevention which has developed an integrated and modern public health surveillance strategy and by HAS documents $[5,3]$. Two risk management systems are considered in our model fig. 2

\subsubsection{Care safety system}

\subsubsection{Integrated public health surveillance}

It includes the notifiable disease surveillance system and certain infectious and non-infectious diseases monitored under public health programs [6].

The first step will consist in identifying the actors and partners to constitute a taskforce which will conceptualize in accordance with the central level, a standard reporting tool despite the difference in the characteristics of the diseases. That would minimize the big number of reporting tools. The standard tool conceptualized could be shared on a computer platform so that the information would be available quickly and reaches the recipient on time under the responsibility of the SRES facilitator assisted by the hospital referents.

\subsubsection{Adverse event monitoring system}

This is about care-related incidents and accidents which the resolution and corrective measures are carried out by the hospital teams. The healthcare teams can communicate adverse events to the care coordinator who notifies to either the nosocomial infection committee (C.L.I.N) in the case of nosocomial infections, to the occupational physician in the case of exposure to blood, burn out or other occupational accident and to the regional pharmacology center in the case of occurred drug adverse effects. An IT tool common to healthcare services is desirable to ensure the traceability, reliability and data sharing.

This standard tool will also include information related to neonatal deaths as recommended by the focus group.

In addition, we could consider an active surveillance carried out by the care coordinator who will have the task of visiting all clinical services twice a day and collecting adverse events. The choice of the care coordinator comes from the fact that he is present at the hospital according to a 24-hour on-call system and that his mission allows him to be in contact with all clinical, administrative and logistical services and could thus do promoting the reporting of adverse events. 


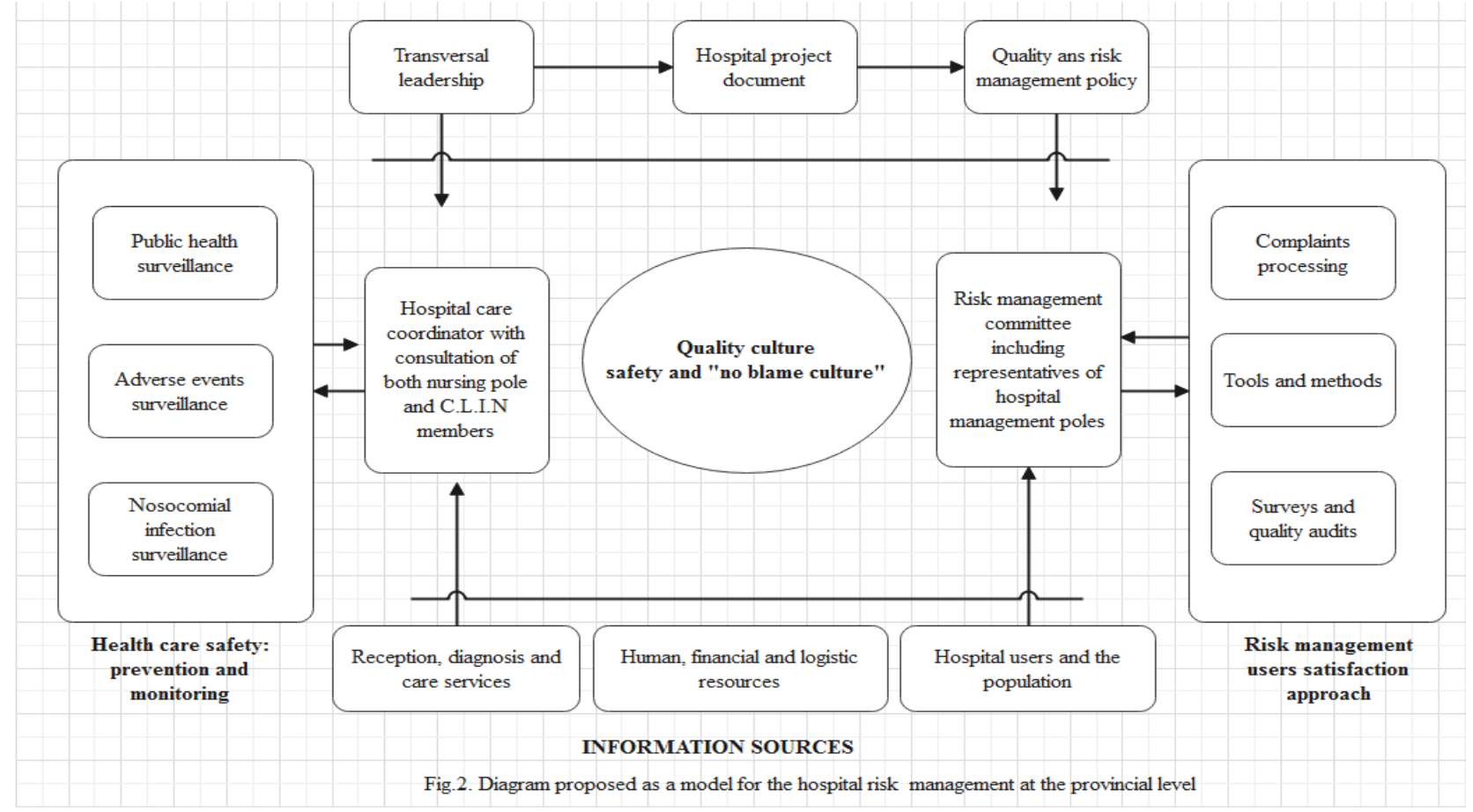

\subsection{Risk management for hospital user satisfaction approach}

The handling of claims and complaints from users contributes considerably to improving the quality of care. We suggest that the unit dedicated to this activity, consisting of the quality responsible, administrative members and social workers, collect complaints sent by mail, reported orally or electronically, on a database. These claims and complaints can have an internal source (hospital staff), or an external source (patients and population). The head of the unit mobilizes the management committees, made up of the heads of the poles (administrative pole, nursing care pole, medical affairs pole) who meet within a week to investigate the complaint or claim, find solutions and write a response to the complainant or an investigation report. This activity used to address complaints relating to hospital front office, organization and health worker deviant behavior. We suggest to add in this approach, the management of risks reported from claims related to other malfunctions such as equipment, transportation and hospital installations maintenance. Reports on catering and accommodation services should be analyzed by the management committees to provide suggestions for quality improvement. These committees should be well skilled to conduct quality audits and enquiries and provide reports that contribute to decision making.

\subsection{Common points to the two systems}

Both of the 2 systems « health care safety » and « risk management for user satisfaction », must make it possible to manage risks in advance by producing risk source sheets and risk mapping for well-known risks. Then, to be able to find post-incident solutions and promote good practices. A risk management program common to the two systems established in a cross-cutting manner should promote prevention and protection. A communication plan must accompany each phase of the building program.

For drug-related adverse reactions, the experience of computerization developed in the context of the covid-19 pandemic, could be capitalized on for the collection of both drug and vaccine adverse reactions. In addition, while awaiting the completion of the medical patient record computerization project, these two surveillance systems will work in coordination to manage risks and share information. The recommended active surveillance will make it possible to circumvent the workload constraint mentioned by caregivers during the focus groups. A continuous training program in risk management is essential to support the implementation of this model.

\section{Conclusion}

This model is essentially based on cross-cutting management which takes into account the different processes and missions of the hospital. Inspired by the literature [3,7], it must be break-down from a managerial policy that clearly defines roles, responsibilities and coordination mechanisms. Its sustainability depends on the principles of transparency, integration and information sharing. It proposes a better organization of the flow of risk management information at the hospital level, which will considerably improve the quality of care. However, its success depends on 3 key components health workers capacity-building, hospital records accuracy and computerizing. 


\section{Acknowledgements}

We would like to thank all the staff of the Ifrane CHP who participated in the focus groups.

\section{References}

1. P. M Hudson. WHO MNH/PSF/94.3. Entretien de groupe: concepts, usage et ancrage II, 29, n 3, ISSN 1715-8702 Geneva (1994) -

http://www.recherchequalitative.qc.ca/Revue.html, (2011)

2. S. Dawson, L. Mandersen and V.L.Tallo. A manual of the use of focus groups, WHO, UNDP/ word bank ; INFDC Boston (1993)

3. HAS. La sécurité des patients. Mettre en œuvre la gestion des risques associés aux soins en établissement de santé. Des concepts à la pratique. France (2012 ) www.hassante.fr

4. WHO. La qualité des services de santé : un impératif mondial en vue de la couverture santé universelle. ISBN 978-92-4-251390-5. (2019)

https://apps.who.int/iris/bitstream/handle/106

5. CDC, Office of Public Health Scientific Services. Public Health Surveillance: Preparing for the Future. Atlanta (2018)

6. P. Nsubuga, M.E. White, S.B. Thacker, M.A. Anderson, S.B. Blount, C.V. Broome, T.M. Chiller, V.Espitia, R. Imtiaz, D. Sosin, D.F. Stroup, R.V. Tauxe, M.Vijayaraghavan, and M.Trostle. Public Health Surveillance: A Tool for Targeting and Monitoring Interventions in Disease Control Priorities in Developing Countries. 2nd edition. The World Bank; Chapter 53, 997-1013. Washington (DC) (2006)

7. SDS. Governance as a transversal theme. An Implementation Guide Governance Division, SDC governance@deza.admin.ch (2007) 